\title{
Dealing with complex overactive bladder syndrome patient profiles with focus on fesoterodine: in or out of the EAU guidelines?
}

This article was published in the following Dove Press journal:

Research and Reports in Urology

31 October 2017

Number of times this article has been viewed

John Heesakkers'

Montserrat Espuña Pons ${ }^{2}$

Philip Toozs Hobson ${ }^{3}$

Emmanuel Chartier-Kastler ${ }^{4}$

'Department of Urology, Radboud University Medical Center, Nijmegen, Netherlands; 'Pelvic Floor Unit, ICGON, Hospital Clinic de Barcelona, University of Barcelona, Barcelona, Spain; ${ }^{3}$ Department of Urogynecology, Birmingham Women's Hospital, Birmingham, UK; ${ }^{4}$ Department of Urology, Academic Hospital PitiéSalpêtrière, Assistance PubliqueHôpitaux de Paris, Pierre et Marie Curie Medical School, Paris 6 University, Sorbonne Universités, Paris, France
Correspondence: John Heesakkers Department of Urology, Radboud University Medical Center, 10 Geert Grooteplein Zuid, Nijmegen 6525 GA, Netherlands

$\mathrm{Tel}+3$ I 2436 I 3735

Email John.Heesakkers@radboudumc.nl
Abstract: Overactive bladder (OAB) syndrome is a common, complex, and challenging condition. To assist the management of these patients, the European Association of Urology (EAU) updates its guidelines annually. This review reports the presentations from the symposium titled "Dealing with complex OAB patient profiles: in or out of the EAU guidelines?" held at the 32nd EAU Annual Congress in March 2017 in London. The symposium focused on three groups of OAB patients: women who may also suffer pelvic organ prolapse, stress urinary incontinence, the genitourinary syndrome of menopause (GSM); patients at risk of cognitive impairment; and elderly patients. The aim of the symposium was to determine how the 2017 EAU guidelines can best assist physicians, as well as to assess the benefits of fesoterodine in these patients. The EAU guidelines recommend antimuscarinic agents (grade A) for the medical treatment of OAB. In women, OAB is correlated with GSM, both of which are underdiagnosed and undertreated. Fesoterodine decreases $\mathrm{OAB}$ symptoms and the associated limitation of physical activity. A combination of fesoterodine and vaginal estrogens is appropriate for OAB associated with GSM. In patients at risk of cognitive impairment, prescribers should pay particular attention to the choice of medication. Fesoterodine is a Pgp substrate with limited ability to cross the blood-brain barrier, which may explain the lack of negative effects on the central nervous system observed in clinical trials of this agent. OAB should not be regarded as a normal consequence of aging. Fesoterodine has been extensively investigated in the elderly, and is the only anticholinergic drug licensed for OAB in this population, rated B (beneficial) according to the Fit for the Aged classification for lower-urinary-tract symptoms. The EAU guidelines are a valuable resource for physicians managing patients with $\mathrm{OAB}$, and the pharmacological properties of fesoterodine offer credible clinical advantages in these three patient groups.

Keywords: cognitive function, elderly, fesoterodine, guidelines, overactive bladder, women

\section{Introduction}

Overactive bladder (OAB) syndrome is defined as "urinary urgency, with or without urgency urinary incontinence [UUI], usually with increased daytime frequency and nocturia, in the absence of infection or other obvious pathology". ${ }^{1,2}$ OAB can be a complex and challenging syndrome in certain patient groups. The prevalence of OAB is increasing worldwide in association with the growth of the aging population, with $11 \%$ of the global population affected in 2008 and predicted to increase to $20 \%$, or 546 million individuals, by $2018 .^{3} \mathrm{OAB}$ has a greater impact on the social and functional domains of quality of life (QL) than that of diabetes. ${ }^{4}$

The diagnosis and management of OAB merits particular attention, given that this syndrome can affect many patient groups: both men and women, those with other 
comorbidities, and those taking a mix of medications. ${ }^{5}$ As a result, the onus is on the physician to collect an accurate history, examine the patient, and investigate if other causes can better explain the symptoms, and then to treat the patient accordingly. The European Association of Urology (EAU) guidelines ${ }^{6}$ have been developed to assist health-care professionals in dealing with complex cases in a structured way based on the available evidence. These are updated every year, and form a framework for clinicians to assist in the diagnosis and management of OAB.

This review reports on lectures given at the symposium "Dealing with complex OAB patient profiles: in or out of the EAU guidelines?" held at the 32nd Annual Congress of the EAU in March 2017 in London. The symposium, sponsored by Pierre Fabre Laboratories, aimed to answer the question: Do these guidelines help the physician in dealing with challenging patient groups, or should we vary from them? It focused on three challenging patient groups: women who may also suffer from pelvic organ prolapse (POP), stress UI (SUI) or the effects of menopause; OAB patients at risk of cognitive impairment; and elderly patients, in whom the prevalence of OAB is high and whose specificities are important to consider. The EAU recommendations for these three patient groups, as well as the published evidence on fesoterodine, ${ }^{7}$ an antimuscarinic agent, are presented and discussed.

\section{Management of women with OAB $O A B$ is frequently unrecognized in} women

Data collected in Belgium from women aged 40 years or over visiting their general practitioner for any reason who answered the Bladder Control Self-Assessment Questionnaire (B-SAQ) revealed that $18 \%$ of them were affected by moderate-severe SUI and a third had mild bladder-control symptoms. ${ }^{8}$ In this study, urgency and nocturia were found to be the most bothersome (higher score of bother on the B-SAQ) symptoms. In another study, ${ }^{9}$ women from the Finnish population register were contacted to assess the bother associated with 12 different lower-urinary-tract symptoms (LUTS). From an individual perspective, UUI was found to be the symptom most likely to be rated as bothersome by patients and SUI was second. Women and men with OAB symptoms report that OAB affects their health-related QL (HRQL): they have significantly poorer work productivity, sexual satisfaction, higher rates of major depressive symptoms, and less physical activity than controls. ${ }^{10,11}$ Despite this, many women do not seek medical assistance,,${ }^{9,12}$ leaving the disorder unrecognized.

\section{$O A B$ is a dynamic disease, particularly in women}

In Austria, women with OAB (21-81 years) were followed for a mean of 6.5 years. The prevalence of OAB was $19 \%$ at baseline and $27 \%$ at the end of the study. With time, remission occurred in $40 \%$ of women, improvement occurred in $12 \%$, disease was stable in $41 \%$, and it progressed in $7 \%$. Therefore, natural history shows that $\mathrm{OAB}$ is a dynamic disease that can have a long-lasting and stable course, remit, or progress with age. ${ }^{13}$

\section{Sex differences in OAB show that women are more often bothered by symptoms}

The OAB prevalence found in the EPIC study was $12 \%$, and it reached $16 \%$ in the National Overactive Bladder Evaluation (NOBLE) program in the US, with no significant differences between women and men. However, the type of symptoms may differ. For instance, UI seems to be more frequent in women ( $13 \%$ versus $5 \%$ in men in the EPIC study). Women $(66 \%)$ were more likely to be bothered by frequency of urination than men $(46 \%) .{ }^{14}$

\section{Specific risk factors for women}

In Sweden, OAB prevalence, measured in female twins from the Swedish twin registry, was $19 \%$ in those who had a history of gestational diabetes mellitus (GDM) and 11\% in women without GDM. After adjusting for age, parity, body-mass index (BMI), DM, and smoking, GDM was associated with almost-doubled odds of OAB (OR 1.88, 95\% CI 1.26-2.8). ${ }^{15}$

A systematic review of observational studies on $\mathrm{OAB}$ and metabolic syndrome, a cluster of risk factors that includes central obesity, dyslipidemia, hypertension, insulin resistance, and glucose intolerance, concluded that there was a link between OAB and metabolic syndrome. ${ }^{16}$ Women with a BMI $>30$ are twice as likely to have $\mathrm{OAB}$ with urge incontinence than women with a BMI $<24 .{ }^{14}$ Weight loss should be encouraged, in addition to therapy for OAB symptoms.

In a cross-sectional Dutch study, ${ }^{17}$ POP symptoms were present in $11 \%$ of women. The prevalence of urgency, frequency, UI, or any OAB symptoms was significantly increased in those with POP. Treatment of this independent risk factor was able to improve OAB symptoms. The other risk factors found in this study were incontinence surgery in the past, age $>75$ years, overweight, and postmenopausal status.

Genitourinary syndrome of menopause (GSM), formerly called vulvovaginal atrophy (VVA), has been designated to facilitate the identification of $\mathrm{VV}$ and urinary estrogen deprivation-associated signs and symptoms. GSM includes 
genital symptoms of dryness, burning, and irritation; impaired sexual function with lack of lubrication, discomfort, or pain; and urinary symptoms with frequency, nocturia, urgency, SUI, and urinary-tract infections when other vulvar and urinary pathologies possibly responsible for similar symptomatology have been excluded. ${ }^{18}$

The female lower urinary tract is a target organ for estrogens, and estrogen deprivation leads to changes in periurethral tissues (decrease in collagen) and urethral mucosa (atrophy). This could be the rationale for the use of estrogen supplementation in the treatment of the LUTS disorders of postmenopausal women. ${ }^{19,20}$ In the AGATA study, ${ }^{21}$ among postmenopausal women asking for a routine gynecological examination, 79\% were diagnosed with GSM based on the patient's sensation of vaginal dryness, any objective sign of VVA and a $\mathrm{pH}>5$. Patients also reported dyspareunia (78\%), burning (57\%), itching (57\%), and dysuria (36\%). Only 30\% of participants had been previously diagnosed with VVA. GSM appeared to be highly prevalent, underdiagnosed, and inadequately treated. Conserved sexual function may prevent or delay the loss of vaginal elasticity. ${ }^{21}$ In another study ${ }^{22}$ in 45- to 60-year-old women, vaginal dryness was associated with a greater $\mathrm{OAB}$ prevalence (ratio $1.75, P=0.012$ ). Health professionals should adopt a proactive response to women with genital atrophy to identify and treat $\mathrm{OAB}$.

Robinson et $\mathrm{a}^{23}$ reported that $70 \%$ of women relate the onset of UI to their final menstrual period, corresponding to estrogen decrease. First-line therapies include vaginal moisturizers and lubricants, ${ }^{24}$ however, estrogen therapy remains the standard therapy for symptomatic women who suffer from moderate-severe GSM. Local treatment is preferred. There are few absolute contraindications for estrogen use, especially if used topically. ${ }^{25}$ Even in breast cancer patients, there are now data suggesting that ultralow-dose topical estriol can be used safely, with excellent results in improving vaginal microflora, quality of sex life, and urinary function. ${ }^{26}$ The estrogen-antimuscarinic combination could be a good option to treat OAB in women with GSM.

\section{Fesoterodine in women with $O A B$}

The primary goals of pharmacological therapy for women with $\mathrm{OAB}$ are to relieve symptoms and improve HRQL. In a pilot study, ${ }^{27}$ menopausal patients with OAB symptoms were treated either with fesoterodine $4 \mathrm{mg}$ /day for a week and then with $8 \mathrm{mg} /$ day if tolerance was good, or with the same dosage of fesoterodine combined with topical vaginal estrogens once daily. After 12 weeks, the fesoterodine-alone group showed a significant improvement in OAB symptoms, as measured with the Overactive Bladder Questionnaire -short form $(P<0.0001)$, HRQL $(P=0.0002)$, and Sexual Quality of Life - female (SQOL-F; $P=0.02$ ). Compared to fesoterodine alone, the combination group showed a reduction in OABsymptom severity ( 10 versus $23.3, P=0.35$ ), higher HRQL score (96.9 versus $84.6, P=0.75$ ), and higher SQOL-F score (99 versus $81, P=0.098$ ).

In a prospective study ${ }^{28}$ women with $\mathrm{OAB}$ were treated with flexible doses of fesoterodine combined with behavioral counseling over 8 weeks. Physical activity was assessed using two questions of the Short Form 12 and categorized into three levels of limitation: none, moderate, or severe limitations Women treated with fesoterodine reported less bother from urinary symptoms and fewer restrictions in physical activity, showing that fesoterodine reduces the impact of $\mathrm{OAB}$ on physical activity.

The SAFINA ${ }^{29}$ trial defined the goals of OAB patients, mainly women (80\%), using the Self-Assessment Goal Achievement questionnaire. Patients were treated with flexible doses of fesoterodine for 12 weeks. Patients' treatment aims were more focused on the completion of tasks, rather than on reducing particular symptoms. With regard to symptoms, the most frequently expressed goals were to reduce nocturia, urgency, and frequency. At the end of the study, $81 \%$ of patients treated with fesoterodine declared that their goals were "somewhat achieved", "achieved", or "greatly exceeded/exceeded their expectations".

\section{EAU guidelines for $O A B$}

The 2017 EAU guidelines ${ }^{6}$ for women presenting with UI recommend (after initial assessment and discussion of OAB management) that patients are offered individual behavioral and physical therapies. When medical treatment is advised, antimuscarinic agents are recommended (grade A). The EAU recommendations dedicated to women meet the conclusions of the studies presented, notably:

- on risk factors: "Encourage obese women with UI to lose weight and maintain weight loss (grade A)"

- on activity: "Counsel female athletes experiencing UI with intense physical activity that it will not predispose them to UI in later life (grade C)"

- on estrogen therapy: "Offer postmenopausal women with UI vaginal estrogen therapy, particularly if other symptoms of VVA are present (grade A)"; "Vaginal estrogen therapy for VVA should be prescribed long-term. In women with a history of breast cancer, the treating oncologist needs to be consulted (grade C)". 


\section{Dealing with OAB in patients at risk of cognitive impairment Specific factors in patients at risk of cognitive impairment}

Being prefrail or frail, having a functional comorbidity index (number of comorbidities $0-18$ ) $\geq 2$, and being aged $\geq 85$ years have been found to be associated with anticholinergic medication use.$^{30}$ However, one of the major issues of treating these patients is the difficulty in assessing their exposure to and impact of drugs with anticholinergic effects. The serum anticholinergic assay has been proposed as a measure of anticholinergic burden, but assay levels do not necessarily reflect the treatment used by the patient. ${ }^{30}$ Few patients report central nervous system (CNS) symptoms, because they are not able to recognize the cognitive impairment or changes in memory or may think these are related to aging and not to their medications. ${ }^{31}$ The effects of anticholinergics on cognition vary substantially among studies. This may be due to several factors, including age, clinical condition, and the medicines used. ${ }^{30,32}$ Recognition of how many drugs the patient is taking and the variety of different therapeutic areas they involve, including antihistamines, antidepressants, antiemetics, antipsychotics, muscle relaxants, and antivertigo, cardiovascular, gastrointestinal, or antiparkinsonian drugs, which have anticholinergic properties ${ }^{33}$ is important, and they should be identified as such. Patients can be considered at risk of cognitive impairment where there is preexisting CNS impairment or when they take multiple medications or some with anticholinergic activity, particularly when oxybutynin is used in vulnerable elderly patients..$^{31,34}$

\section{The role of the blood-brain barrier}

The blood-brain barrier (BBB) is a complex, heterogeneous, and dynamic membrane at the level of the cerebral capillaries that limits the entry of unwanted molecules into the brain. Antimuscarinic agents cross the BBB via passive diffusion according to their lipophilicity and molecular weight. ${ }^{34-38}$ Some antimuscarinics are removed from the brain via an active transport mechanism facilitated by Pgp, which limits the levels of drugs in the brain. The BBB can be impaired by different causes, including aging, medication, or systemic diseases (inflammatory; neurodegenerative diseases, such as Alzheimer's, Parkinson's disease, and multiple sclerosis; vascular conditions; neoplasia; brain edema; meningitis; and trauma). ${ }^{34,39}$

\section{Fesoterodine in $O A B$ patients at risk of cognitive impairment}

As a result of its pharmacological properties, fesoterodine crosses the BBB poorly, which in fact is an advantage in terms of any potential negative effect on cognitive function. It has the highest molecular weight of the antimuscarinics and low lipophilicity (Table 1); moreover, the active moiety of fesoterodine, 5-HMT, is pumped out of the brain by Pgp, an efflux transporter. ${ }^{7,33,38,40-42}$ Trospium is a quaternary amine and a hydrophilic molecule that does not cross the BBB.

The effect of fesoterodine on cognitive function has been evaluated in a crossover study ${ }^{43}$ where healthy older individuals (mean age 72.2 years) received over four different periods fesoterodine $4 \mathrm{mg} \times 6$ days, fesoterodine $4 \mathrm{mg}$ $\times 3$ days + fesoterodine $8 \mathrm{mg} \times 3$ days, placebo $\times 6$ days, or placebo $\times 6$ days with alprazolam $1 \mathrm{mg}$ on day 6 . A battery of cognitive tests (detection task, identification task, onecard learning task, continuous paired-associate learning task, Groton maze learning task, and the Rey auditory verbal learning test) were performed on days 1 and 6 of each period. Unlike alprazolam, which induced sedation and a large and statistically significant deterioration, fesoterodine at doses of $4 \mathrm{mg}$ and $8 \mathrm{mg}$ showed no statistically significant effects compared with placebo on any of the cognitive functions, including memory.

The effects of flexible-dose fesoterodine were tested in a double-blind, placebo-controlled Vulnerable Elderly Study. ${ }^{44}$ Vulnerable elderly subjects were defined as having a risk of deteriorating health with a score $\geq 3$ on the Vulnerable Elders Survey (VES) 13 and a score $\geq 20$ on the MiniMental State Examination (MMSE), indicating possible mild cognitive impairment (MMSE maximum score 30, scores $\geq 27$ correspond to normal cognition, 20-26 indicate some cognitive impairment). In both the placebo and fesotero-

Table I Pharmacological and pharmacokinetic properties of antimuscarinic agents

\begin{tabular}{llllllll}
\hline Molecules & Oxybutynin & Tolterodine & Trospium & Propiverine & Darifenacin & Solifenacin & Fesoterodine/5-HMT \\
\hline Molecular weight & 393.9 & 475.6 & 427.97 & 403.95 & 507.5 & 480.55 & 527.66 \\
Lipophilicity & $>3.3$ & I.83 & -1.22 & Lipophilic & 2.7 & 1.69 & 0.74 \\
Pgp substrate & No & No & Yes & No & Yes & No & Yes \\
\hline
\end{tabular}

Notes: Data from Chancellor and Boone, ${ }^{31}$ Cetinel and Onal, ${ }^{33}$ Kerdraon et al, ${ }^{38}$ Malhotra et al. ${ }^{42}$ Copyright (C) 20II. MHRA. Adapted from Medicines and Healthcare Products Regulatory Agency. Public assessment report - mutual recognition procedure: Mictonorm XL 45 mg modified release capsules (propiverine hydrochloride). 20 II. Available from: http://www.mhra.gov.uk/home/groups/par/documents/websiteresources/con I 43796.pdf. ${ }^{40}$

Abbreviation: HMT, hydroxymethyl tolterodine. 
dine groups, patients had a high number of comorbidities (mean number per patient slightly over eight, range one to 27) and comedications (mean number per patient slightly over eight, range one to 40). Treatment with a flexible dose of fesoterodine over 12 weeks showed significantly greater efficacy versus placebo in reducing the mean number of UUI episodes and micturitions per 24 hours. There was no decrease in mean MMSE scores for subjects receiving fesoterodine or placebo, showing that fesoterodine did not worsen cognitive impairment. Fesoterodine was well tolerated, with a safety profile comparable to that seen in other studies in younger populations. The most frequent adverse events were a dry mouth and constipation, and no new safety signals were identified.

\section{EAU guidelines and cognitive function}

The 2017 EAU guidelines contain a specific chapter dedicated to antimuscarinic agents, the elderly, and cognition, and recommend caution notably in the long-term use of antimuscarinic treatment in elderly patients, especially those who are at risk of, or have, cognitive dysfunction. Moreover the total antimuscarinic load has to be evaluated and if additional antimuscarinic load is to be avoided the use of mirabegron should be considered. ${ }^{6}$

Concerning antimuscarinic agents, the EAU guidelines state that "solifenacin, darifenacin, fesoterodine, and trospium have been shown not to cause cognitive dysfunction in elderly people". ${ }^{6}$

\section{Elderly with OAB Specific factors in elderly patients with $\mathrm{OAB}$}

Although the prevalence of $\mathrm{OAB}$ increases with age, it should not be considered a normal consequence of aging. ${ }^{45}$ Treatment should be chosen on an individual basis, taking into account tolerability, absence of drug interactions, and cognitive safety. ${ }^{46} \mathrm{OAB}$ and UUI in the elderly may have serious consequences, notably in cases of nocturia. Elderly women with UI have a $26 \%$ higher risk of falls and $34 \%$ greater risk of fractures. Urgency and UUI significantly predict 10-year mortality in men, and UUI significantly predicts mortality in women. ${ }^{47-49}$ The OAB Re-Contact Study, a self-reported Internet survey in patients aged 65 years or over, demonstrated that diagnosed versus undiagnosed and treated versus untreated respondents had better mental scores, better QL, and less impairment of their activity. ${ }^{50}$

\section{Fesoterodine in elderly patients}

Fesoterodine possesses four interesting pharmacological properties that give it a therapeutic profile adapted to many OAB patients, including the elderly. ${ }^{51-53}$ Firstly, fesoterodine's active metabolite, 5-HMT, has limited ability to cross the BBB, and as a Pgp substrate, it is actively pumped out of the brain. As a result, fesoterodine presents a safe profile with respect to cognitive impairment. Secondly, the molecule does not undergo first-pass hepatic metabolism, but is metabolized by ubiquitous peripheral esterases that are not dependent on the individual's enzymatic equipment and not affected by age. This property might explain the consistency of response across patients and the consistent results in clinical trials. Thirdly, fesoterodine is a prolonged-release medication, permitting once-daily dosing. Finally, fesoterodine has a balanced affinity for $\mathrm{M}_{2}$ and $\mathrm{M}_{3}$ receptors. All muscarinicreceptor subtypes have been detected in the human bladder; however, the $M_{2}$ and $M_{3}$ receptors seem to be the most important in the regulation of the complex process of bladder function. The $M_{2}$ subtype outnumbers the $M_{3}$ subtype, and is the most highly expressed in the urothelium of the human bladder. However, $\mathrm{M}_{3}$ receptors are thought to be most important for detrusor contraction, which is decreased in cases of blockade by anti- $\mathrm{M}_{3}$ agents. ${ }^{54,55}$ Both subtypes are coupled to $G$ proteins, but their signal-transduction pathways $\operatorname{differ}^{54}$ (Figure 1). Activation of $\mathrm{M}_{2}$ receptors reverses the sympathetic $\beta$-adrenoreceptor-mediated relaxation of the detrusor. Therefore, by blocking $\mathrm{M}_{2}$ receptors with $\mathrm{M}_{2}$ antimuscarinic agents, fesoterodine inhibits this effect, resulting in bladder relaxation and an increase in bladder capacity. ${ }^{56}$ The $\mathrm{M}_{2}$ receptor might also play an indirect role in mediating

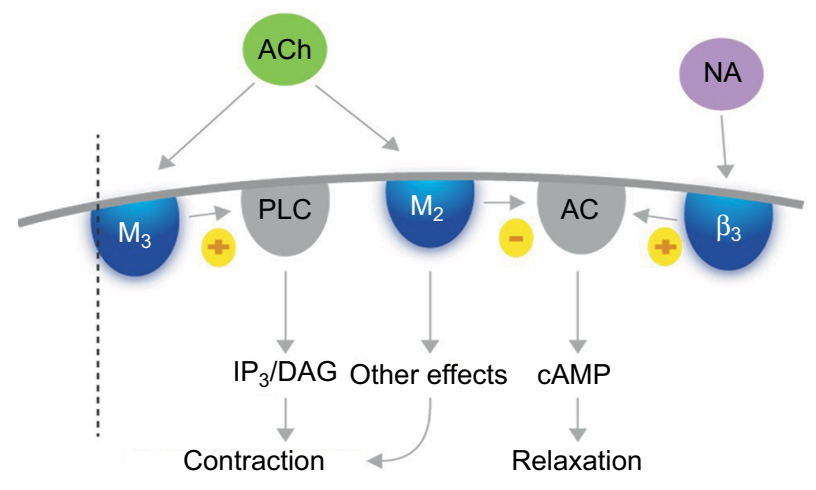

Figure I Actions of acetylcholine on $M_{2}$ and $M_{3}$ receptors.

Notes: Stimulation of $M_{3}$ receptors activates PLC and phosphoinositide hydrolysis, leading to inositol triphosphate $\left(\mathrm{IP}_{3}\right)$ and diacylglycerol (DAG) formation, inducing calcium release and detrusor contraction. $M_{2}$ receptors inhibit $A C$, and may aid bladder contraction by reversing CAMP-induced relaxation. Data from Abrams and Andersson, ${ }^{54}$ Sellers and Chess-Williams, ${ }^{55}$ and Chapple. ${ }^{56}$

Abbreviations: ACh, acetylcholine; cAMP, cyclic adenosine monophosphate; NA, noradrenaline; $\beta_{3}$, beta- 3 adrenergic receptor; $M_{2}, M_{3}$, muscarinic receptors. 
bladder contraction by enhancing the contractile response to $\mathrm{M}_{3}$-receptor activation, and minor $\mathrm{M}_{2}$-receptor-mediated contractions might also occur. Moreover, in some disease states, the contribution of $\mathrm{M}_{2}$ receptors to detrusor contraction might increase. ${ }^{54}$ The result of fesoterodine's balanced $\mathrm{M}_{2}-\mathrm{M}_{3}$ affinity is a double effect on contraction control and relaxation.

Several studies have evaluated the efficacy and safety of fesoterodine in elderly OAB patients. In the SOFIA study in an aging population, ${ }^{57}$ patients aged 65 years or older were randomized to fesoterodine or placebo and treated for 12 weeks. Approximately a third of participants were older than 75 years. At week $4,52 \%$ of patients treated with fesoterodine chose to increase their dose from $4 \mathrm{mg}$ to $8 \mathrm{mg}$, with a further $16 \%$ choosing to increase their dose similarly at week 8 , and only $4 \%$ reduced their dose during the study, supporting the use of flexible dosing in an elderly population. In comparison with placebo, fesoterodine induced a statistically significant decrease in urgency episodes per 24 hours, in nocturnal micturitions, and incontinence-pad use, with an improvement in QL and a reduction in symptom-bother scores. The rate of severe dry mouth was low (3\%).

Most of the patients who completed the SOFIA study continued in an open study for a further 12 weeks. ${ }^{58}$ The subjects who had received fesoterodine during the double-blind phase maintained the improvement in urgency episodes over the open-label phase, and had a lower percentage of dry mouth and constipation ( $7 \%$ and $2 \%$, respectively, versus $28 \%$ and $6 \%$ in the group that had received placebo in the double-blind phase), as well as a lower discontinuation rate due to adverse events (4\% versus $10 \%$ ). Constipation is usually considered an adverse event; however, in this age-group, which frequently shows irritable bowel disease and loose stools, constipation could have a positive impact and can even improve QL. ${ }^{59}$

A pooled post hoc analysis of trials ${ }^{60}$ exploring the efficacy and safety of fesoterodine in elderly patients demonstrated a significant decrease in UUI episodes per 24 hours in three groups $(<65,65-74$, or $\geq 75$-years of age $)$ of patients treated with fesoterodine $(8 \mathrm{mg})$ and a higher positive treatment response (improved or greatly improved) in patients treated with fesoterodine ( 4 and $8 \mathrm{mg}$ ) than with placebo in the three age-groups, with a dose-dependent effect.

The Fit for the Aged (FORTA) classification ranks medical treatments according to the level of evidence provided by prospective control studies performed in elderly patients. This results from a systematic independent literature review of studies aimed at evaluating the elderly population through an international consensus-validation process and an independent quality assessment of variation within the studies. The FORTA classification was first established for cardiology medications, and is now used for different kinds of treatments. It guides physicians as to the suitability of medicines for older patients in an everyday clinical setting, and includes four categories (Table 2). In urology, FORTA-LUTS classifies the appropriateness of oral drugs for long-term treatment of LUTS in older persons. Fesoterodine is classified $\mathrm{B}$ (beneficial), and has the highest level of evidence of the available OAB treatments. Most of the other antimuscarinic agents are classified as $\mathrm{C}$ (careful), because the few studies that have been performed in aging patients were not prospective, but involved post hoc or subgroup analyses of data. ${ }^{61}$

A cost-analysis study ${ }^{62}$ evaluating the treatment costs of vulnerable ( $\geq 65$ years with a VES score $\geq 3$ and risk of deteriorating health) $\mathrm{OAB}$ patients and including fesoterodine-drug costs, health-care resources, and OAB-related comorbidities (falls/fractures, urinary tract infections, depression, and nursing home) found that fesoterodine was cost-saving compared to no OAB pharmacotherapy, and could save US\$1,616 per patient per year. Fesoterodine accounted for only $4 \%$ of the total medical costs in the vulnerable elderly.

\section{$E A U$ guidelines and the elderly $O A B$ patient}

The word "elderly", although not defined, usually refers to individuals 65 years old or over. In addition to guidelines

Table 2 Rating of OAB medical drugs on the LUTS-FORTA classification

\begin{tabular}{lll}
\hline Drug class & Agent & FORTA class \\
\hline Antimuscarinics & $\begin{array}{l}\text { Darifenacin } \\
\text { Fesoterodine } \\
\text { Oxybutynin standard dose/ } \\
\text { immediate release } \\
\text { Oxybutynin low dose/extended } \\
\text { release }\end{array}$ & C \\
& $\begin{array}{l}\text { Propiverine } \\
\text { Solifenacin }\end{array}$ & D (C)* \\
& $\begin{array}{l}\text { Tolterodine } \\
\text { Trospium }\end{array}$ & $\mathrm{C}$ \\
& C (B)*
\end{tabular}


related to cognitive function that also frequently concern elderly patients, the 2017 EAU guidelines recommend that older people being treated for UI should be prescribed nonpharmacological treatments first (grade C). They also consider that antimuscarinic drugs are effective in elderly patients (grade 1B). With natural aging, UI becomes more common and elderly people may require special consideration and specific interventions, taking into account their preferences, but OAB should not be considered a normal consequence of aging.

\section{Discussion}

Some interesting points have been raised during the discussion of the specificities of the three patient groups in light of the existing fesoterodine clinical data and the EAU recommendations. In women, OAB is correlated with GSM, and both are underdiagnosed and undertreated. Antimuscarinics are classed as grade $\mathrm{A}$ in the recommendations for treatment of women with OAB. Fesoterodine is associated with a reduction in OAB symptoms, as well as in perceived limitations in physical activity. Fesoterodine combined with vaginal estrogens is appropriate for women with $\mathrm{OAB}$ associated with GSM.

In all patients, and particularly patients at risk of cognitive impairment, prescribers should be careful with medications. Fesoterodine has a limited ability to cross the BBB and is also a Pgp substrate, which could explain its lack of negative effects on the CNS, as confirmed by clinical evidence. Evaluation of cognitive function in healthy older subjects has confirmed that fesoterodine does not impair it.

Elderly people need careful consideration, and $\mathrm{OAB}$ should not be considered a normal consequence of aging. Fesoterodine offers an interesting combination of pharmacological properties with clinical benefits, and is generally well tolerated in older people. Fesoterodine has been studied extensively in elderly patients, and is the only OAB drug rated FORTA B (beneficial). ${ }^{61}$

In neurological diseases, such as multiple sclerosis, cognitive impairment appears to be linked to neurological lesions and to the degree of disability measured with the Expanded Disability Status Scale. ${ }^{63}$ Cognitive impairment is impacted by the deterioration in neurological status that occurs in this disease. For Parkinson's disease, the impact seems more linked to anticholinergic exposure, as these patients are very sensitive to the side effects of antimuscarinic drugs. ${ }^{64}$ Parkinson's, multiple sclerosis, and also brain-trauma patients, who are sometimes young, are known to be at high risk of cognitive impairment. Tests evaluating cognitive impairment are not routinely performed, and remain within the competence of specialists or appropriately trained physicians.

Another point raised was to determine if drug-induced side effects persist over the duration of treatment or if they recede after a certain time. In a study ${ }^{65}$ investigating the rate of dry mouth in female patients treated with fesoterodine, a greater proportion of women with dry mouth reported improvement in their urinary symptoms, and the authors suggested that dry mouth may be a marker of pharmacological potency. In clinical practice, increasing the fesoterodine dose from $4 \mathrm{mg}$ to $8 \mathrm{mg}$ is generally associated with an increase in the rate of dry mouth; however, women who are satisfied with the improved control of their symptoms may be less troubled by a dry mouth. Usually, there is a balance between efficacy and side effects, which are better tolerated when the patient shows a better response, although important individual variations are observed. The response to treatment is rapid, with the full effect reached at 2-4 weeks. In this respect, in most countries, and especially in the UK, nurses have the skills and can take the time to explore their patients' needs and expectations and explain the possible side effects. Specialist nurse intervention in the management of incontinence has been evaluated in several studies, some showing more active detection of patients, gain in $\mathrm{QL}$, or reduction of symptoms, with high patient satisfaction and cost-effectiveness. ${ }^{66}$ Overall, clinical experience has shown that side effects seem to decrease with time, possibly because of the natural course of the disease, and because the patient adapts their treatment accordingly. Prospective studies evaluating the evolution of side effects after 5 or 10 years have not yet been performed; however, long-term treatment (24 and 36 months) with fesoterodine has been shown to be well tolerated, with no new safety concerns identified. ${ }^{67}$

Our objective here was to discuss the EAU guidelines, though guidelines on UI are available from other societies, such as the National Institute for Health and Care Excellence (NICE, UK) or the American Urologic Association (AUA). These guidelines, which may vary in their recommendations, were compared by Syan and Brucker ${ }^{68}$ in 2016.

\section{Conclusion}

$\mathrm{OAB}$ can be complex in its presentation, and occurs as part of a broader patient profile. The updated EAU guidelines are valuable in assisting physicians with the management of these complex patients. An appropriate assessment of the patient is a prerequisite to applying the EAU guidelines in complex groups of patients, including women who have specific risk factors and conditions; patients at risk of cognitive impairment who may have comorbidities, take multiple medications, or show BBB deterioration; and elderly patients 
who are frequently frail and vulnerable and should be treated with caution. Fesoterodine at doses of $4 \mathrm{mg}$ and $8 \mathrm{mg}$ have been studied extensively in these three patient groups, and has been shown to have pharmacological properties that confer clear clinical advantages: fesoterodine is efficient, irrespective of sex or age, is well tolerated in older and vulnerable patients, and does not cause impairment in cognitive function.

\section{Acknowledgment}

Participation in the satellite symposium "Dealing with complex OAB patient profiles: in or out of the EAU guidelines?" at the 32nd Annual Congress of the EAU in March 2017 in London and writing assistance were sponsored by Pierre Fabre (Castres, France).

\section{Disclosure}

$\mathrm{JH}$ has received support as a consultant/lecturer from Astellas, Allergan, BlueWind, Urogyn BV, and Pierre Fabre, and for scientific studies and trials from Astellas, Boston Scientific, Ipsen, BlueWind, and Urogyn BV. MEP has received support as a consultant/lecturer from Astellas, Boston Scientific, and Pierre Fabre. ECK has received support as consultant and/or lecturer and/or investigator from Astellas, Allergan, Boston Scientific, Coloplast, Ipsen, Medtronic, Pfizer, Lilly, Pierre Fabre, and Uromedica. PTH has received support as lecturer from Astellas, Boston, and Pierre Fabre, and as a consultant from Allergan and Speciality European Pharma. The authors report no other conflicts of interest in this work.

\section{References}

1. Abrams P, Cardozo L, Fall M, et al. The standardisation of terminology of lower urinary tract function: report from the Standardisation subCommittee of the International Continence Society. Neurourol Urodyn. 2002;21(2):167-178.

2. Drake MJ. Do we need a new definition of the overactive bladder syndrome? ICI-RS 2013. Neurourol Urodyn. 2014;33(5):622-624.

3. Irwin DE, Kopp ZS, Agatep B, Milsom I, Abrams P. Worldwide prevalence estimates of lower urinary tract symptoms, overactive bladder, urinary incontinence and bladder outlet obstruction. BJU Int. 2011;108(7):1132-1138.

4. Abrams P, Kelleher CJ, Kerr LA, Rogers RG. Overactive bladder significantly affects quality of life. Am J Manag Care. 2000;6(11 Suppl):S580-S590.

5. Brown JS, McGhan WF, Chokroverty S. Comorbidities associated with overactive bladder. Am J Manag Care. 2000;6(11 Suppl):S574-S579.

6. Burkhard FC, Bosch JL, Cruz F, et al. Urinary incontinence [guidelines]. 2017. Available from: https://uroweb.org/guideline/urinaryincontinence. Accessed July 4, 2017.

7. Toviaz (fesoterodine fumarate) [prescribing information]. 2016. Available from: http://www.medicines.org.uk/emc/medicine/20928. Accessed July 4, 2017.

8. de Ridder D, Roumeguère T, Kaufman L. Overactive bladder symptoms, stress urinary incontinence and associated bother in women aged 40 and above: a Belgian epidemiological survey. Int J Clin Pract. 2013;67(3):198-204.
9. Agarwal A, Eryuzlu LN, Cartwright R, et al. What is the most bothersome lower urinary tract symptom? Individual- and population-level perspectives for both men and women. Eur Urol. 2014;65(6):1211-1217.

10. Coyne KS, Sexton CC, Irwin DE, Kopp ZS, Kelleher CJ, Milsom I. The impact of overactive bladder, incontinence and other lower urinary tract symptoms on quality of life, work productivity, sexuality and emotional well-being in men and women: results from the EPIC study. BJU Int. 2008;101(11):1388-1395.

11. Coyne KS, Sexton CC, Clemens JQ, et al. The impact of OAB on physical activity in the United States: results from OAB-POLL. Urology. 2013;82(4):799-806.

12. Taylor J, McGrother CW, Harrison SC, Assassa PR. Lower urinary tract symptoms and related help-seeking behaviour in South Asian men living in the UK. BJU Int. 2006;98(3):605-609.

13. Heidler S, Mert C, Temml C, Madersbacher S. The natural history of the overactive bladder syndrome in females: a long-term analysis of a health screening project. Neurourol Urodyn. 2011;30(8):1437-1441.

14. Eapen RS, Radomski SB. Gender differences in overactive bladder. Can J Urol. 2016;23 Suppl 1:2-9.

15. Tettamanti G, Iliadou AN, Pedersen NL, Bellocco R, Altman D. Association between gestational diabetes mellitus and subsequent overactive bladder among premenopausal female twins. BJOG. 2013;120(10):1289-1295.

16. Bunn F, Kirby M, Pinkney E, et al. Is there a link between overactive bladder and the metabolic syndrome in women? A systematic review of observational studies. Int J Clin Pract. 2015;69(2):199-217.

17. de Boer TA, Slieker-ten Hove MC, Burger CW, Vierhout ME. The prevalence and risk factors of overactive bladder symptoms and its relation to pelvic organ prolapse symptoms in a general female population. Int Urogynecol J. 2011;22(5):569-575.

18. Portman DJ, Gass ML. Genitourinary syndrome of menopause: new terminology for vulvovaginal atrophy from the International Society for the Study of Women's Sexual Health and the North American Menopause Society. Maturitas. 2014;79(3):349-354.

19. Iosif CS, Bekassy Z. Prevalence of genito-urinary symptoms in the late menopause. Acta Obstet Gynecol Scand. 1984;63(3):257-260.

20. Blakeman PJ, Hilton P, Bulmer JN. Oestrogen and progesterone receptor expression in the female lower urinary tract, with reference to oestrogen status. BJU Int. 2000;86(1):32-38.

21. Palma F, Volpe A, Villa P, Cagnacci A. Vaginal atrophy of women in postmenopause: results from a multicentric observational study - the AGATA study. Maturitas. 2016;83:40-44.

22. Juliato CR, Baccaro LF, Pedro AO, Costa-Paiva L, Lui-Filho J, Pinto-Neto AM. Subjective urinary urgency in middle age women: a population-based study. Maturitas. 2016;85:82-87.

23. Robinson D, Toozs-Hobson P, Cardozo L. The effect of hormones on the lower urinary tract. Menopause Int. 2013;19(4):155-162.

24. Calleja-Agius J, Brincat MP. The urogenital system and the menopause. Climacteric. 2015;18 Suppl 1:18-22.

25. Lethaby A, Ayeleke RO, Roberts H. Local oestrogen for vaginal atrophy in postmenopausal women. Cochrane Database Syst Rev. 2016;(8): CD001500.

26. Buchholz S, Mögele M, Lintermans A, et al. Vaginal estriol-lactobacilli combination and quality of life in endocrine-treated breast cancer. Climacteric. 2015; 18(2):252-259.

27. Chughtai B, Forde JC, Buck J, et al. The concomitant use of fesoterodine and topical vaginal estrogen in the management of overactive bladder and sexual dysfunction in postmenopausal women. Post Reprod Health. 2016;22(1):34-40.

28. Chu CM, Harvie HS, Smith AL, Arya LA, Andy UU. The impact of treatment of overactive bladder on physical activity limitations. J Womens Health (Larchmt). 2016;25(8):801-805.

29. Rantell A, Cardozo L, Khullar V. Personal goals and expectations of OAB patients in the UK. Neurourol Urodyn. 2017;36(4):1194-1200.

30. Lampela P, Paajanen T, Hartikainen S, Huupponen R. Central anticholinergic adverse effects and their measurement. Drugs Aging. 2015;32(12):963-974. 
31. Chancellor M, Boone T. Anticholinergics for overactive bladder therapy: central nervous system effects. CNS Neurosci Ther. 2012;18(2):167-174.

32. Lampela P, Taipale H, Hartikainen S. Association between anticholinergic load and frailty in community-dwelling older people. J Am Geriatr Soc. 2016;64(3):671-672.

33. Cetinel B, Onal B. Rationale for the use of anticholinergic agents in overactive bladder with regard to central nervous system and cardiovascular system side effects. Korean J Urol. 2013;54(12): 806-815.

34. Chancellor MB, Staskin DR, Kay GG, Sandage BW, Oefelein MG, Tsao JW. Blood-brain barrier permeation and efflux exclusion of anticholinergics used in the treatment of overactive bladder. Drugs Aging. 2012;29(4):259-273.

35. Hawkins RA, O'Kane RL, Simpson IA, Viña JR. Structure of the blood-brain barrier and its role in the transport of amino acids. J Nutr. 2006;136(1 Suppl):218S-226S.

36. Geller EJ, Crane AK, Wells EC, et al. Effect of anticholinergic use for the treatment of overactive bladder on cognitive function in postmenopausal women. Clin Drug Investig. 2012;32(10):697-705.

37. Scheife R, Takeda M. Central nervous system safety of anticholinergic drugs for the treatment of overactive bladder in the elderly. Clin Ther. 2005;27(2):144-153.

38. Kerdraon J, Robain G, Jeandel C, et al. [Impact on cognitive function of anticholinergic drugs used for the treatment of overactive bladder in the elderly]. Prog Urol. 2014;24(11):672-681.

39. Zeevi N, Pachter J, McCullough LD, Wolfson L, Kuchel GA. The bloodbrain barrier: geriatric relevance of a critical brain-body interface. J Am Geriatr Soc. 2010;58(9):1749-1757.

40. Medicines and Healthcare Products Regulatory Agency. Public assessment report - mutual recognition procedure: Mictonorm XL $45 \mathrm{mg}$ modified release capsules (propiverine hydrochloride). 2011. Available from: http://www.mhra.gov.uk/home/groups/par/documents/websiteresources/con143796.pdf. Accessed July 4, 2017.

41. Wagg, A, Verdejo C, Molander U. Review of cognitive impairment with antimuscarinic agents in elderly patients with overactive bladder. Int J Clin Pract. 2010;64(9):1279-1286.

42. Malhotra B, Gandelman K, Sachse R, Wood N, Michel MC. The design and development of fesoterodine as a prodrug of 5-hydroxymethyl tolterodine (5-HMT), the active metabolite of tolterodine. Curr Med Chem. 2009;16(33):4481-4489.

43. Kay GG, Maruff P, Scholfield D, et al. Evaluation of cognitive function in healthy older subjects treated with fesoterodine. Postgrad Med. 2012;124(3):7-15.

44. Dubeau CE, Kraus SR, Griebling TL, et al. Effect of fesoterodine in vulnerable elderly subjects with urgency incontinence: a double-blind, placebo controlled trial. J Urol. 2014;191(2):395-404.

45. Erdem N, Chu FM. Management of overactive bladder and urge urinary incontinence in the elderly patient. Am J Med. 2006;119(3 Suppl 1):29-36.

46. Lechevallier-Michel N, Molimard M, Dartigues JF, Fabrigoule C, Fourrier-Réglat A. Drugs with anticholinergic properties and cognitive performance in the elderly: results from the PAQUID study. $\mathrm{Br} J \mathrm{Clin}$ Pharmacol. 2005;59(2):143-151.

47. Nakagawa H, Niu K, Hozawa A, et al. Impact of nocturia on bone fracture and mortality in older individuals: a Japanese longitudinal cohort study. J Urol. 2010;184(4):1413-1418.

48. Brown JS, Vittinghoff E, Wyman JF, et al. Urinary incontinence: does it increase risk for falls and fractures? Am Geriatr Soc. 2000;48(7): 721-725

49. Nuotio M, Tammela TL, Luukkaala T, Jylhä M. Urgency and urge incontinence in an older population: ten-year changes and their association with mortality. Aging Clin Exp Res. 2002;14(5):412-419.
50. Lee LK, Goren A, Zou KH, et al. Potential benefits of diagnosis and treatment on health outcomes among elderly people with symptoms of overactive bladder. Int J Clin Pract. 2016;70(1):66-81.

51. Cardozo L, Khullar V, Wang JT, Guan Z, Sand PK. Fesoterodine in patients with overactive bladder syndrome: can the severity of baseline urgency urinary incontinence predict dosing requirement? BJU Int. 2010;106(6):816-821.

52. García-Baquero R, Madurga B, García MV, Fernández MA, Rosety JM, Álvarez-Ossorio JL. [New perspectives of treatment with fesoterodine fumarate in patients with overactive bladder]. Actas Urol Esp. 2013;37(2):83-91. Spanish.

53. Khullar V, Rovner ES, Dmochowski R, Nitti V, Wang J, Guan Z. Fesoterodine dose response in subjects with overactive bladder syndrome. Urology. 2008;71(5):839-843.

54. Abrams P, Andersson KE. Muscarinic receptor antagonists for overactive bladder. BJU Int. 2007;100(5):987-1006.

55. Sellers DJ, Chess-Williams R. Muscarinic agonists and antagonists: effects on the urinary bladder. Handb Exp Pharmacol. 2012;(208):375-400.

56. Chapple CR. Muscarinic receptor antagonists in the treatment of overactive bladder. Urology. 2000;55(5A Suppl):33-46.

57. Wagg A, Khullar V, Marschall-Kehrel D, et al. Flexible-dose fesoterodine in elderly adults with overactive bladder: results of the randomized, double-blind, placebo-controlled study of fesoterodine in an aging population trial. J Am Geriatr Soc. 2013;61(2):185-193.

58. Wagg A, Khullar V, Michel MC, Oelke M, Darekar A, Bitoun CE. Long-term safety, tolerability and efficacy of flexible-dose fesoterodine in elderly patients with overactive bladder: open-label extension of the SOFIA trial. Neurourol Urodyn. 2014;33(1):106-114.

59. Bulchandani S, Toozs-Hobson P, Parsons M, McCooty S, Perkins K, Latthe P. Effect of anticholinergics on the overactive bladder and bowel domain of the electronic personal assessment questionnaire (ePAQ). Int Urogynecol J. 2015;26(4):533-7.

60. Kraus SR, Ruiz-Cerdá JL, Martire D, Wang JT, Wagg AS. Efficacy and tolerability of fesoterodine in older and younger subjects with overactive bladder. Urology. 2010;76(6):1350-1357.

61. Oelke M, Becher K, Castro-Diaz D, et al. Appropriateness of oral drugs for long-term treatment of lower urinary tract symptoms in older persons: results of a systematic literature review and international consensus validation process (LUTS-FORTA 2014). Age Ageing. 2015;44(5):745-755.

62. Qin L, Luo X, Zou KH, Snedecor SJ. Economic impact of using fesoterodine for the treatment of overactive bladder with urge urinary incontinence in a vulnerable elderly population in the United States. J Med Econ. 2016;19(3):229-235.

63. Rocca MA, Amato MP, De Stefano N, et al. Clinical and imaging assessment of cognitive dysfunction in multiple sclerosis. Lancet Neurol. 2015;14(3):302-317.

64. Perez-Lloret S, Peralta MC, Barrantes FJ. Pharmacotherapies for Parkinson's disease symptoms related to cholinergic degeneration. Expert Opin Pharmacother. 2016;17(18):2405-2415.

65. Weissbart SJ, Lewis R, Smith AL, Harvie HS, Miller JM, Arya LA. Impact of dry mouth on fluid intake and overactive bladder symptoms in women taking fesoterodine. J Urol. 2016;195(5):1517-1522.

66. Holtzer-Goor KM, Gaultney JG, van Houten P, et al. Cost-effectiveness of including a nurse specialist in the treatment of urinary incontinence in primary care in the Netherlands. PLoS One. 2015;10(10):e0138225.

67. Chapple C, Oelke M, Kaplan SA, Scholfield D, Arumi D, Wagg AS. Fesoterodine clinical efficacy and safety for the treatment of overactive bladder in relation to patient profiles: a systematic review. Curr Med Res Opin. 2015;31(6):1201-1243.

68. Syan R, Brucker BM. Guideline of guidelines: urinary incontinence. BJU Int. 2016;117(1):20-33. 
Research and Reports in Urology is an international, peer-reviewed, open access journal publishing original research, reports, editorials, reviews and commentaries on all aspects of adult and pediatric urology in the clinic and laboratory including the following topics: Pathology, pathophysiology of urological disease; Investigation and treatment of urological disease; Pharmacology of drugs used for the treatment of urological disease. The manuscript management system is completely online and includes a very quick and fair peer-review system, which is all easy to use. Visit http://www.dovepress.com/testimonials.php to read real quotes from published authors

Submit your manuscript here: https://www.dovepress.com/research-and-reports-in-urology-journal 